\title{
COMPARATIVE STUDY BETWEEN TWO DIFFERENT OSTEOSYNTHESIS DEVICES FOR FIXATION OF SUBCONDYLAR FRACTURE
}

\author{
Hanan M. Shokeir", Shadia A. Elsayed ${ }^{* *}$ and Ghada A. Khalifa***
}

\begin{abstract}
Statement of problem: Management of subcondylar fracture with proper reduction of temporomandibular joint position and function is a challenge, different osteosynthesis devices are used with great diversity in their types, numbers, positions, and results.

Purpose: Comparative study between the efficiency of single miniplate and single minidynamic compression plate in restoration of ramus height, condylar angulation, and tempromandibular joint function in subcondylar fracture cases.

Material and Method: 14 patients indicated for open reduction and fixation of subcondylar fractures were divided into two groups each of 7 patients. Group A: subcondylar fractures were fixed using 2.0 single miniplate along posterior border of ramus. Group B: a single 2.0-mm minidynamic compression plates (DCP), were applied along posterior border of ascending ramus for fracture fixation in the other seven patients. Intermaxillary fixation for 10 days was applied for both groups. Clinical and radiograhic follow up were performed at 1,3,6 months using panorama and CT.
\end{abstract}

Results: At 6 months postoperatively, there was an improvement of mandibular functions with improvement of inter-incisal opening from $19.1 \mathrm{~mm}$ and $20.1 \mathrm{~mm}$ in group A and B respectively to $35.6 \mathrm{~mm}$ and $30.8 \mathrm{~mm}$. Which was significantly different ( $\mathrm{P}$ value $=0.04)$. The shortening in ramus height improved from $3.2 \mathrm{~mm}$ and $5.2 \mathrm{~mm}$ in group A and B to $0.8 \mathrm{~mm}$ and $0.6 \mathrm{~mm}$, also sagittal angulation of condyle improved from $1.6^{\circ}$ and $4.7^{\circ}$ in both group respectively to $0.2^{\circ}$ and $0.3^{\circ}$ with no significant difference between two types of mini-plate. There were no signs of infection, malunion, nonunion or device failure in both groups. except for one case of group A, that suffered from malocclusion with displacements of the fractured segments immediately after the operations, that responded to elastic traction within 15 days.

Conclusion: Single $0.2 \mathrm{~mm}$ miniplate or mini DCP aided by intermaxillary fixation are successful devices in fixation of subcondylar fracture without complication, with superiority of mini DCP in proper condylar reduction and stable fixation.

\footnotetext{
* Associate Professor of Oral and Maxillofacial Surgery, Faculty of Dental Medicine for Girls, Al-Azhar University. ** Lecturer of Oral and Maxillofacial Surgery, Faculty of Dental Medicine for Girls, Al-Azhar University

*** Associate Professor of Oral and Maxillofacial Surgery, Faculty of Dental Medicine for Girls, Al-Azhar University.
} 


\section{INTRODUCTION}

Condylar fractures are common fractures that accounting for $29-52 \%$ of mandibular fracture and $11-16 \%$ of facial fractures ${ }^{(1,2)}$. Roughly one-third of mandibular fractures occur in the condylar region. However, depending on etiology, the frequency can vary from about $22 \%$ to $67 \%$. In most cases, condylar fractures can be treated conservatively with the best results, even in cases of fracture with dislocation. The opinion has been expressed that surgery should normally be reserved for cases of bony ankylosis, for example, following intracapsular fractures, unreduced major condylar dislocation, especially if bilateral that can lead to an open bite, severe dysfunction of the jaws and pain. ${ }^{(3)}$

Open reduction and Plating of subcondylar fractures allow patients to have immediate mobilization, better oral hygiene, improved nutrition, normal speech, occlusion, masticatory function, mouth opening, bone morphology and better functional reconstruction of mandibular condyle compared to non-surgical closed reduction methods. ${ }^{(4,5)}$

Open reduction and fixation also overcomes the complications of closed reduction as malocclusion, diminished posterior facial height, and decreased mandibular motion. ${ }^{(6)}$

Open reduction and fixation can be done either intra-orally or extraorally, inspite of the easier intraoral approach with preservation of facial nerve, and better esthetics without facial scarring, but it is indicated in special cases of very low subcondylar fracture that are laterally displaced, otherwise It is technically difficult, inaccessible, and need for endoscopic assistance. ${ }^{(7)}$

Extraoral approach represent about $70 \%$ with proper accessibility and visualization, in spite of the great risk of facial nerve injury and scarring but severely displaced and high positioned fractures are indicated for extra-oral approach .Internal fixation using bone plates were the most widely used fixation technique for subcondylar fracture $(79 \%)$ $\&$ using of 2 miniplates along anterior and posterior border of ramus during fixation of subcondylar fracture are advised as a strong plating results in functionally stable osteosynthesis, with first plate placed along the posterior axis of the condylar neck for reduction, and the second one is placed below and parallel to sigmoid notch to restore tensile strain lines during function. However, the use of two miniplates requires adequate access with wide surgical exposure, increase the danger of damaging the facial nerve. Also, it is difficult to put 4 screws in the condylar fragment because of limited bony surface. ${ }^{(15)}$

Results of 40 miniplate osteosynthesis. Performed on displaced low subcondylar fractures of the mandible in single form are presented with better results ${ }^{(8)}$, with restoration of the anatomical form shown on X-ray, no functional disorder restricting mandibular motion. The results indicated that miniplate osteosynthesis is practically feasible and recommended as a therapy depending on the particular indication.

Other clinical study ${ }^{(9)}$ have shown that, single straight miniplate is inadequate in fixation of subcondylar fracture, with possibility of mechanical failure due to plate fracture, instability, and screw loosening.

Ellis and Dean ${ }^{(10)}$, advocate using mini compression plates in subcondylar fracture as it's stronger than the adaptation miniplate. Also Single dynamic compression is thick and can reduce the fracture in subcondylar area using the mechanical advantages of the compression plate that can better neutralize function stress at condylar neck, as the highest level of compression occurs on the posterior surface of condylar neck. ${ }^{(10,11)}$

So the aim of the present study was to compare between single miniplate and single minidynamic compression plate regarding their efficiency in restoration of ramus height, condylar angulation, and temporomandibular joint function. 


\section{PATIENTS AND METHODS}

14 patients suffering from subcondylar mandibular fractures were selected. The patients attended Al Zahraa University Hospital, Al Azhar University between October 2009 and October 2014 with no sex predilection. The patient's age ranged from 19 to 38 years with an average 27.5 years.

The selected cases were indicated for open reduction and internal fixation as condylar fracture associated with concomitant fractures elsewhere in the mandible for which mobilization was necessary. Patients with comminuted fractures, or a systemic disease that could have interfered with healing (e.g., diabetes, chemotherapy) were excluded from this study. All patients were informed about the proposed mode of treatment and provided written informed consent to undergo surgery. Prior to surgery, full histories and clinical examinations were performed and recorded on a standardized sheet. Preoperative digital panoramic radiographs were used for the initial assessments of the following: the line or lines of the fractures, the location of the inferior alveolar canal, and the degree of displacement. Other necessary views, such as postero-anterior views or computed tomography (CT) were requested as necessary for each case. The selected patients were categorized into two groups, with 7 patients in each group, according to the type of hardware used for fracture fixation, as follows:

Group A: included 7 patients with subcondylar fractures who were treated with single $2.0-\mathrm{mm}$ mini-plates.

Group B: included 7 patients with subcondylar fractures who were treated with single $2.0-\mathrm{mm}$ mini DCPs.

Presurgical procedure: All patients received intravenous antibiotics from the time of admission until surgery (Unasyn 1.5 gm every 12 hours), followed by a 5 - to 7-days course of oral antibiotics post-surgically(Augmentin 1 gm every 12 hours).
Arch bars with maxillomandibular fixation (MMF) were applied preopcrativcly in every patient, and if the occlusion was not perfect, elastic traction was used as a guide for occlusion and central line 3-5 days before surgical intervention.

Surgical procedures: Under general anesthesia using naso-endotracheal intubation and halothane/ 02gas mixture plus local anesthesia (Mepecainc -local anesthesia with vasoconstrictor levonordefrin 1:20000 at operative field), the fracture wasexposed using an extraoral submandibular incision, followed by intraoperative manipulation of the fractured segments after exposure of the fracture line until proper occlusion achieved. The MMF was secured after occlusion adjustment and central line of the jaws. Reduction of the fractured segments was then performed. The fracture site and dislocated condylar segments are well visualized and are palpated with a finger so now easy to manipulate without any hindrance. Then holding the proximal segment of condyle by kochcr clamp to reduce it. If the condyle is dislocated medially, a periosteal elevator is used to manipulate the condyle laterally, manual inferior traction of the mandible on the fractured side using traction wire or towel clamp along angle of the mandible help in proper seating of condylar segment. (IMF was done by elastics to allow for some adjustment of the distal segment). After confirming the anatomic reduction and repositioning of the condylar segment, the tip of a periosteal elevator is placed on the lateral surface of the condyle to hold the fragment in place during the fixation process.

In group A, 2.0-mm single miniplate with 4 holes (Oswald Leibinger $\mathrm{GmbH}$, Germany) was adapted along the lateral border of the mandible and secured with $2.0-\mathrm{mm}$ self-tapping screws. Accurate adaptation of the miniplate was done to avoid displacement of the fractured segments. The first screw was not tightened until the second screw on the other side of the fracture is completely 
placed to prevent movement of the plate into an undesirable position, the fracture reduction was facilitated by pulling the miniplate. The second screw was then placed in the distal mandibular fragment through one of the holes in the miniplate after supporting this segment using Channel retractor, and a screw is placed securely. Attention was given to proper alignment of the posterior border of the ramus, by visual inspection and digital palpation. The remaining screws were inserted to tightly osteosynthesize the bone fragments using the lengths of the screws that ranged between 6 and $10 \mathrm{~mm}$ that allowing for the bicortical fixation. The bicortical screws provided sufficient rigidity to the fragments to prevent interfragmentary mobility during active use of the mandible and to overcome the biomechanical forces in the mandibular condyle, and at least two screws were inserted on either side of the fracture. (Figure 1)

In group B, a 2.0-mm DCP (AO/ASIF Arbeitsgemeinschaft für Osteosynthese Fragen; Mandible 2-0; Synthes Maxillofacial, Paoli, PA, USA) 4,

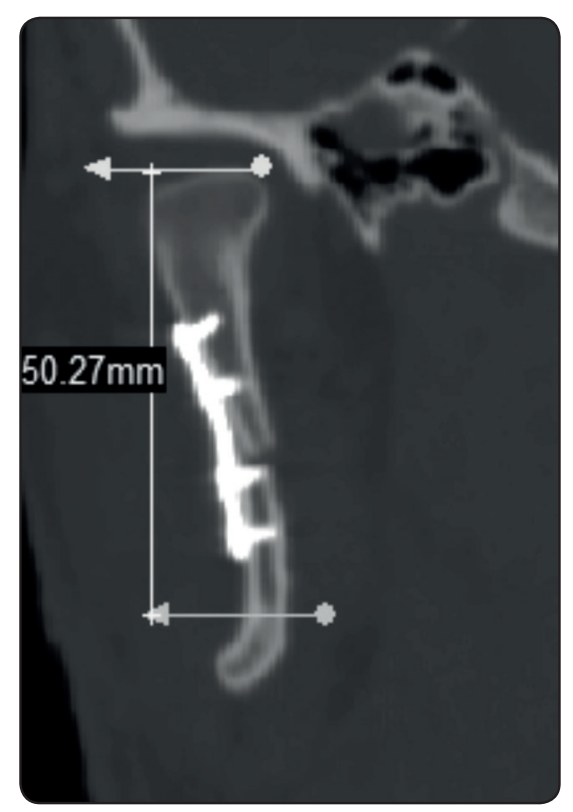

Fig. (1) CT showing one month postoperative for case of subcondylar fracture, Group A using single miniplate with measurement of ramus height. holes plate was selected. The plate was bent at room temperature and then fitted on the posterior border buttress of the mandibular ramus, with the same technique used for the group A. The occlusion of all patients was checked by releasing the MMF to confirm stable and reproducible occlusion. MMF then was removed; the occlusion, the central line and mandibular movement were checked to ensure that there were no discrepancies in opening, closing, and occlusion. (Figure 2)

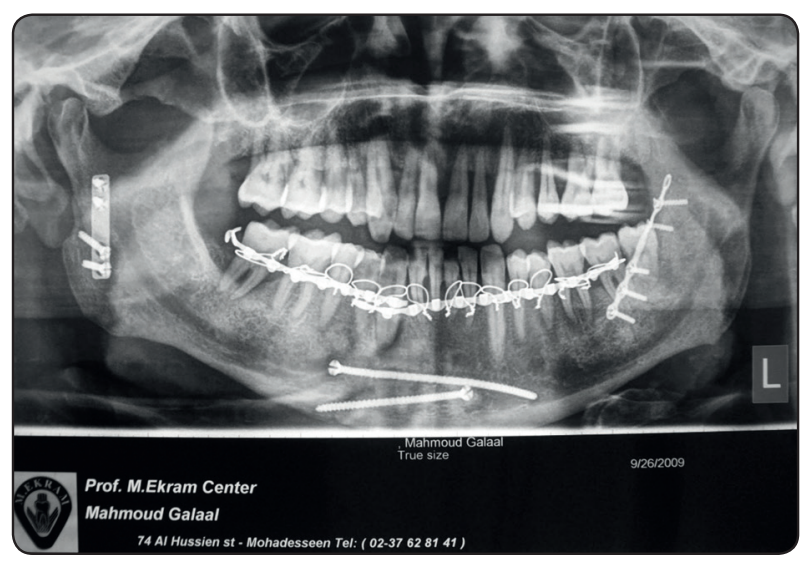

Fig. (2) Panoramic radiograph showing reduction of subcondylar fracture in group B using single miniDCP.

The wound was revised for any bleeding points to ensure homeostasis. The incision sites were irrigated with normal saline solution and closed; no drains were placed. Concomitant fractures in mandibular areas other than the condyles were treated with double 2.0-mm miniplates in all patients before condylar fixation, and the patient were placed into MMF for 10 days. Dressing was applied extraorally to reduce edema. After MMF release; physiotherapy was initiated with soft diet for two weeks to prevent temporomandibular joint ankylosis. The surgical times of each group were calculated retrospectively to avoid bias. The durations involving hardware placement only, begin at the end of the fracture reduction to the final insertion of the hardware into the bone. 
Clinical follow-ups were performed in the first week, first, third and six months postoperatively. The following outcomes were recorded: union and stability at the fracture site (based on digital palpation), presence of soft tissue infection, mandibular movement range, the patient's tolerance of the device, malocclusion, inter-incisal opening, quality of the external scar, facial nerve weakness, sensory nerve injury, and the need for plate removal.

Postoperative radiographs including orthopantomogram, and computed tomography, to evaluate the degree of bone healing, to measure the restoration of normal height of mandibular ramus after proper reduction and fixation, and to evaluate the related complications such as screw failure or loosening, malunion and nonunion.

1. Orthopantomogram, immediate, 1, 3,6 months. To measure sagittal angulation of condyle at fractured side. (Figure 3)

2. Computed tomography (CT): coronal, axial, sagittal views at 1,3,6 months, to measure ramus height, and sagittal angulation of fractured side.

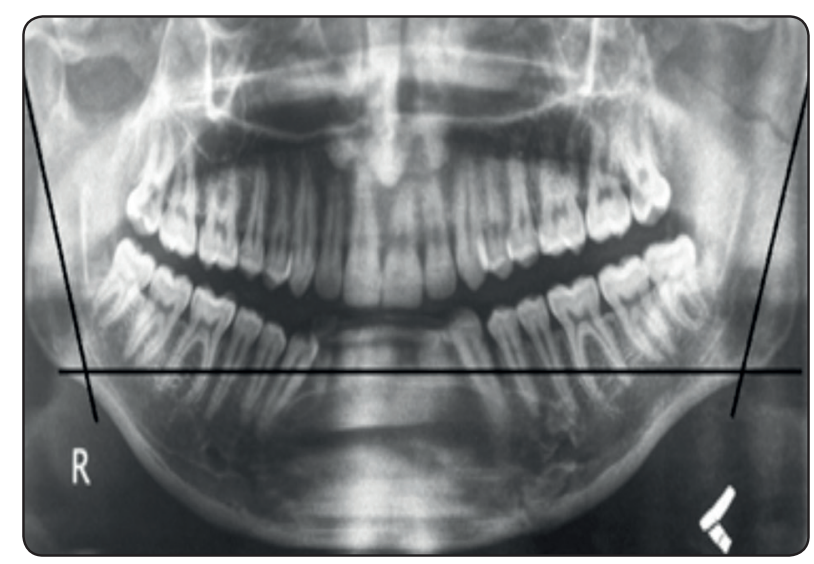

Fig. (3) Photograph showing line method by which sagittal displacement was measured on panorama.

\section{Statistical methods}

Collected data were recorded, tabulated, and analyzed statistically. The data were analyzed with Microsoft Office XP (Excel) and SPSS version
16.00 software (SPSS Inc., Chicago, IL, USA). Parametric data were expressed as the mean standard deviation (SD), and non-parametric data were expressed as the number and percentage of the total. Difference s between groups were examined with $\mathrm{x} 2$ tests, and significance was set at the 0.05 level (P-value <0.05).

\section{RESULTS}

The patients' demographic data were collected and recorded. The patients ranged in age from 19 to 38 years; with a mean of 27.5 years. $85.7 \%$ $(n=12)$ were male. The most common etiology of the mandibular subcondylar fracture was motorcycle accident $(50 \%, \mathrm{n}=7)$, followed by car accident $(21.4 \%, \mathrm{n}=3)$, falls $(14.3 \%, \mathrm{n}=2)$ and altercations $(14.3 \%, \mathrm{n}=2)$. All of the patients presented with displaced linear subcondylar fractures, eight of them had contralateral undisplaced parasymphyseal fractures $(57.1 \%)$, three patients $(14.3 \%)$ had body fractures and 3 patients $(21.4 \%)$ had angle fractures on the contralateral side. The level of subcondylar fracture was below the level of the sigmoid notch with adequate bone stock available in the condylar stump for retention of at least 2 screws.

All patients had an indication for open reduction with internal fixation to reposition the condylar segment and ensure stability of the occlusion. These indications included inability to achieve adequate occlusion with closed reduction, significant displacement or dislocation of the condylar stump or significant loss of ramus height secondary to subcondylar fracture revealed by deviation of the mandible to fractured side.

All patients had Pain on palpation or movement. Two patients had preoperative normal occlusion, ten patients had ipsilateral premature contact at posterior teeth, and two patients had anterior open bite.

All patients had sufficient dentition for support of posterior ramus height on the fracture side. 
Pain, swelling, and mal-occlusion were the most common symptoms among all patients preoperatively. Four patients $(28.6 \%)$ also suffered from hematoma related to the sites of the fractures. The demographic data revealed no significant differences between the groups for any of the preoperative variables. With regard to intra-operative variables, significant differences were found between the groups for surgical time and cost.

\section{Clinical evaluation:}

Operative time: The shortest surgical time was observed in group A $(33.5 \ldots 4.7 \mathrm{~min})$, followed by group B (mean $42.8 \_6.3 \mathrm{~min}$ ); this difference was highly significant $(\mathrm{P}=0.009)$. The difference in duration between groups A and B arose because the miniDCP required more plate adaptation. The insertion of screws in both groups presented some difficulties, particularly the higher ones which increased the surgical time in both groups.

Pain, joint function, and occlusion: The majority of the patients (11 patients) reported moderate pain at the first postoperative visit, which resolved by the second to third week after surgery. Clinical evaluations and radiographic examinations did not demonstrate any non-unions, malunions, or improper occlusion in these patients, with the exceptions of one case in group A (14.2\%). who exhibited displacements of the fractured segments immediately after the operations, with occlusal discrepancies, that responded to elastic traction within 15 days with stable occlusion. No TMJ dysfunction observed in both groups except for increased TMJ sounds in both groups. In all patients no infection occurred at subcondylar fractures postoperatively. Facial nerves were not affected in any of our patients. The results of this study indicated no significant differences between two groups in any of the above parameters.

Range of movements and inter incisal distance: The range of movement was assessed postoperatively by evaluation of maximal mouth opening, protrusion, lateral excursion, and deviation in closing and opening. All patients regained normal inter-incisal opening and mandibular movement by the end of the fourth week after surgery, with improvement of inter-incisal distance from 19.1 $\mathrm{mm}, 20.1 \mathrm{~mm}$ in group A and B prcoperatively (nonsignificant difference $P$ value $=0.7$ ) to $35.6 \mathrm{~mm}$ and $30.8 \mathrm{~mm}$ respectively with no shift of central line. Which was significantly different $(\mathrm{P}$ value $=0.04$ ) at 6 months postoperatively . Table 1

Sagittal angulations of condyle: The average degree of preoperative sagittal angulations of fracture condyle which measured on the panoramic $\mathrm{x}$-ray was $1.6^{0}, 4.70^{\circ}$ in both groups $\mathrm{A}$ and $\mathrm{B}$ respectively. That became $0.2^{0}$ and $0.3^{\circ}$ which was statistically non-significant between the two plates $(\mathrm{P}$ value $=0.6)$, at 6 months postoperatively. Table 2

Ramus height: The average pretreatment shortening of the ascending ramus was $3.2 \mathrm{~mm}$ and $5.2 \mathrm{~mm}$ on CT in both group A and B respectively, that decreased to $0.8 \mathrm{~mm}$ and $0.6 \mathrm{~mm}$ at 6 months postoperatively in both groups, with a nonsignificant difference between them, $(\mathrm{P}$ value $=0.1$, 0.7). Table 3

CT scans showed alignment of condylar head with the ramus, in addition to relation of condylar head to the glenoid fossa. Erosion, osteophyte formation or sclerosis of condylar process were not observed in any patient of our study groups. 
TABLE (1) Mean and t test between preoperative and postoperative interincisal opening of both groups

\begin{tabular}{|c|c|c|c|c|c|c|}
\hline & Group & N & Mean & Std. Deviation & Std. Error Mean & Sig. (2-Tailed) \\
\hline \multirow{2}{*}{$\begin{array}{c}\text { Preoperative Mouth } \\
\text { Opening }\end{array}$} & Single Miniplate & 7 & 19.1429 & 5.66947 & 2.14286 & .716 \\
\cline { 2 - 7 } & Single MiniDCP & 7 & 20.1429 & 4.29839 & 1.62464 & .57143 \\
\hline \multirow{2}{*}{$\begin{array}{c}\text { One Month Postoperative } \\
\text { Mouth Opening }\end{array}$} & Single Miniplate & 7 & 35.5714 & 1.51186 & 1.99319 & .042 \\
\cline { 2 - 7 } & Single MiniDCP & 7 & 30.8571 & 5.27347 & \\
\hline
\end{tabular}

TABLE (2) Mean and standard deviation of preoperative and postoperative condylar sagittal angulations of both groups

\begin{tabular}{|c|c|c|c|c|c|c|}
\hline & Group & N & Mean & Std. Deviation & Std. Error Mean & Sig. (2-Tailed) \\
\hline \multirow{2}{*}{$\begin{array}{c}\text { Preoperative Condylar } \\
\text { Sagittal Angulations }\end{array}$} & Single Miniplate & 7 & 1.6286 & 2.07020 & .78246 & .009 \\
\cline { 2 - 7 } & Single MiniDCP & 7 & 4.7857 & 1.72861 & .65335 & .12697 \\
\hline $\begin{array}{c}\text { Postoperative Condylar } \\
\text { Sagittal Angulations }\end{array}$ & Single Miniplate & 7 & .2571 & .33594 & .16741 & .691 \\
\cline { 2 - 7 } & Single MiniDCP & 7 & .3429 & .44293 & \\
\hline
\end{tabular}

TABLE (3) Mean and standard deviation of preoperative and postoperative ramus height loss of both groups

\begin{tabular}{|c|c|c|c|c|c|c|}
\hline & Group & N & Mean & Std. Deviation & Std. Error Mean & Sig. (2-Tailed) \\
\hline \multirow{2}{*}{$\begin{array}{c}\text { Preoperative Ramus } \\
\text { Height Loss }\end{array}$} & Single Miniplate & 7 & 3.2143 & 2.41276 & .91194 & .125 \\
\cline { 2 - 6 } & Single MiniDCP & 7 & 5.2857 & 2.28869 & .86504 & .75981 \\
\hline \multirow{2}{*}{$\begin{array}{c}\text { Postoperative Ramus } \\
\text { Height }\end{array}$} & Single Miniplate & 7 & .8000 & 1.21655 & .739 \\
\cline { 2 - 6 } & Single MiniDCP & 7 & .6143 & .77121 & .29149 & \\
\hline
\end{tabular}

\section{DISCUSSION}

Surgical treatment of subcondylar fractures was the treatment of choice inspite of the controversy in the current literatures about the complication of surgical intervension, but as a rule intracapsular fracture and fracture in children are best managed conservatively, while extracapsular fractures in adults as present in our study, especially with great condylar displacement is indicated for open reduction and internal fixation, and this agree with different literatures ${ }^{(12,13)}$ who support open reduction and internal fixation with good results in terms of occlusion, bone morphology and articular function.

Submandibular approach for extra-oral access allowed good subcondylar fracture visualization and treatment in comparison to intraoral approach that need to be assisted by endoscope with special indications, special devices and trained expertise, also it is superior to preauricular approach that expose the tempromandibular joint probably but with limited access for plating. ${ }^{(13)}$ 
Using of single miniplate in both groups along the posterior border, aimed at reduction of tissue retraction with its complication, more time saving, and less hard ware used, as usage of two miniplates requires adequate access with wide surgical exposure, which may increase the danger of damaging the facial nerve. Also it is difficult in most cases to put 4 screws in the condylar fragment with limited bony surface. ${ }^{(15)}$

Intermaxillary fixation postoperatively was mandatory with the single plating in both groups aimed at approximation and closure of fracture line at tension zone along the anterior border of ramus, this in accordance with champay et al ${ }^{(14)}$. who concluded that the superior and inferior border of the mandible were subjected to tensile and compressive forces respectively. With respect to masticatory forces transmitted through condylar process, Kessler ${ }^{(15)}$ suggested that the posterior border of the ramus is subjected to compressive strain, while tensile strain is applied along the anterior border below mandibular notch due to muscle pull. ${ }^{(16)}$

Macroscopically, improper fixation in subcondylar fracture with early mobilization results in slippage of the condyle fragment postroinferiorly after loading, which resulted in an antroposterior gap of approximately $2 \mathrm{~mm}$. ${ }^{(16)}$

The success of single plating with intermaxillary fixation was confirmed by absence of any signs of fracture opening along the tension zone clinically and radiographically, no infection, no mlocclusion and or nonunion in both groups with improvement in joint function and restoration of ramus height and condyle angulation, as this combination of fixation support the subcondylar fracture with increasing interfragmentry stability, decreasing the mechanical strains arising in condylar region with undisturbed healing in the correct anatomic position and stable conditions. ${ }^{(17)}$

In spite of the insignificant difference between results in both group, but minidynamic compression proved better results in the condyle angulation and ramus height than with 0.2 miniplate, this was confirmed by the success of all cases of mini DCP without any fixation change or failure during follow up periods in comparison to the occlusion discrepancy that affect one case of 2.0 mini plate group this may be referred to more strength properties and resistance of mini DCP to the rotational force applied to the stabilized condyle without bending. ${ }^{(18)}$

In-vitro experimental results on an osteotomized tibia fixed by miniplate 2.0 in one group, one minidynamic compression 2.0 in another group and two miniplates in the third group (one mini and one minidynamic compression both of $0.2 \mathrm{~mm}$ ) concluded that more stable fixation load is obtained with use of 2 plates than single miniplate, in addition that, the load measured with one dynamic showed a higher deformation and failure load than the load measured in the two adaptation plate, with conclusion that single dynamic compression provides a stable load than single miniplate when treating subcondylar fracture. ${ }^{(10,19)}$.

\section{CONCLUSION}

Good centric occlusion and proper condyle reduction and fixation were more stable by using single MINI DCP with supplemental 10 days of MMF.

\section{REFERENCES}

1- Chrcanovic B R: open versus closed reduction diacapitular fractures of mandibular condyle. Oral Maxillofac Surg. 2012 Sep; 16(3):257-65

2- Zhou HH, Liu Q, Ceng G, Li ZB: Aetiology, pattern and treatment of mandibular condyler fractures in 549 patients: a 22 year retrospective study. J Craniomaxillofac Surg. 2013 Jan; 41(1):34-41

3- Mikkonen P, Lindqvist C, Pihakari A, Iizuka T, Paukku P. Osteotomy - osteosynthesis in displaced condylar fractures. Int J Oral Maxillofac Surg. 1989 Oct; 18(5): 267-70. 
4- Throckmorton GS, Ellis E 3rd, Hayasaki H. Masticatory motion after surgical or nonsurgical treatment for unilateral fractures of the mandibular condylar process. J Oral Maxillofac Surg. 2004 Feb; 62(2):127-38.

5- Brandt MT, Haug RH. Open versus closed reduction of adult mandibular condyle fractures: a review of the literature regarding the evolution of current thoughts on management. J Oral Maxillofac Surg. 2003 Nov; 61(11):1324-32.

6- Ellis 3rd E, Throckmorton G. Facial symmetry after closed and open treatment of fractures of mandibular condylar process. J Oral Maxillofac Surg. 2000 Jul; 58(7):719-28; discussion 729-30.

7- Schneider M, Lauer G, Eckelt U. Surgical treatment of fractures of mandibular condyle: a comparison of long term results following different approachesfunctional, axiographical, and radiographic findings. J Craniomaxillofac Surg. 2007 Apr; 35(3):151-60

8- Gerlach K.L., Mokros S., Erie A. Miniplate Osteosynthesis of Low Subcondylar Fractures of the Mandible by Intraoral Approach: Indications. Method, Results.J Cranio maxillofac Surg.1996Aug;24(1):47.

9- Neff A, Chossegros C, Blanc JL, Champsaur P, Cheynet F, Devauchelle B, Eckelt U, Ferri J, Gabrielli MF, Guyot L, Koppel DA, Meyer C, Müller B, Peltomäki T, Spallaccia F, Varoquaux A, Wilk A, Pitak-Arnnop P. Position paper from the IBRA Symposium on Surgery of the Head-the 2nd International Symposium for Condylar Fracture Osteosynthesis, Marseille, France 2012. J Craniomaxillofac Surg. 2014 Oct; 42(7):1234-49.

10- Ellis E, 3 rd, Dean J. Rigid fixation of mandibular condyle fractures. Oral Surg Oral Med Oral Pathol. 1993 Jul; 76(1):6-15.
11- Choi BH, Kim KN, Kim HJ, Kim MK. Evaluation of condylar neck fracture plating techniques. J Craniomaxillofac Surg. 1999 Apr; 27(2):109-12

12- Mikkonen P, Lindqvist C, Pihakari A, Iizuka T, Paukku P. Osteotomy - osteosynthesis in displaced condylar fractures. Int J Oral Maxillofac Surg. 1989 Oct; 18(5):267-70.

13- Quted from Ellis III E and Zlde MF. Surgical Approaches to the Facial Skeleton. Williams and Wilkins: Philadelphia, 1995

14. Champy M, Lodde JP, Jaeger JH, Wilk A. Mandibular Osteosynthesis according to the Michelet technique. I Biomechanical bases. Rev Stomatol Chir Maxillofac. 1976 Apr-May; 77(3):569-76.

15- Kessler W. Das Spannungsoptische Oberflachenschichtverfahren zur mechanischen spannungmeessung am menschlichen Unterkiefer unter physiologischer Belasstung. Medical Dissertation, Munich:University of Munich:1980 (in German)

16- Christopoulos P, Stathopoulos P, Alexandridis C, Shetty $\mathrm{V}$, Caputo A. Comparative biomechanical evaluation of mono-cortical osteosynthesis systems for condylar fractures using photoelastic stress analysis. Br J Oral Maxillofac Surg. 2012 Oct; 50(7):636-41

17- Vineeth K, Lalitha RM, Prasad K, Singh J. A comparative evaluation between single non-compression titanium miniplate in treatment of mandibular angle fracture-a randomized prospective study. J Craniomaxillofac Surg. 2013 Mar; 41(2):103-9.

18- Rallis G, Mourouzis c, Ainatzoglou M, Zachariades N. Plate osteosynthesis of condylar fractures; a retrospective study of 45 patients. Quintessence Int. 2003 Jan; 34(1):45-9.

19- Lee W, Kang DH. Study of the plating methods in the experimental mandibular subcondyle fracture. J Korean cleft palate-craniofac Assoc. 2011: 12; 12-16. 